\title{
Editorials
}

\section{Near peer teaching in general practice}

The need for clinical training placements in general practice is quietly spiralling. One reason for this is growth in medical student numbers, but experience in general practice is also increasingly regarded as central to the educational needs of other healthcare trainees, including nurses, pharmacists, allied health professionals, and, more recently, physician associates. This demand is partly driven by changing patterns of patient care, but also by growing recognition of general practice as an ideal environment for learning, among other things, clinical skills, the generalist approach, and the value of longitudinal patient care. Such recognition is both welcome and overdue, but inevitably stretches capacity in a service already under significant pressure, and many practices may feel unwilling or unable to take on expanded teaching and training roles.

Part of the answer to this paradox may be staring us in the face. GP trainees represent a large, well-placed, but underutilised educational resource. They can make valuable contributions as near peer teachers', particularly in the context of undergraduate medical education. Engaging their potential in this way could not only help meet teaching capacity, but also encourage and prepare the clinical educators of tomorrow. Yet despite the development of teaching skills forming an expected outcome in the Royal College of General Practitioners training curriculum, it appears that GP trainees are currently much less engaged with teaching activities than their hospital trainee peers.

\section{GP TRAINEE PERSPECTIVE}

GP trainees are enthusiastic to gain experience of teaching prior to completion of training, yet are not often provided with the training or opportunities to do so. Studies suggest that around $60 \%$ of GP trainees are involved in some teaching, and $90 \%$ desire further training in this field. ${ }^{2}$ In many cases, however, GP trainees who teach do so only informally and occasionally, often through ad hoc opportunities with little prior notice or time to prepare.

Such findings are disappointing given the growing evidence of benefits of near peer teaching. Teaching is a well-recognised driver of learning and trainees who teach have been shown to demonstrate enhanced knowledge retention compared with peers who do not. ${ }^{4}$ Through teaching, trainees develop a range

$$
\begin{aligned}
& \text { "Harnessing the energy and skills of GP trainees as } \\
& \text { near peer teachers is a relatively simple measure } \\
& \text { that could significantly increase the capacity for GP } \\
& \text { placements for medical students and other health } \\
& \text { professionals in training." }
\end{aligned}
$$

of skills that positively impact not only on selfreported clinical ability, but also more generic workplace skills such as self-reflection, time management, and leadership. ${ }^{5}$ Furthermore, trainees in teaching roles deliberately adopt good clinical practice as a result of learner observation.

\section{MEDICAL STUDENT PERSPECTIVE}

Medical students seem often to prefer trainee-delivered teaching compared with teaching by senior clinicians. By being closer in age and stage, trainees are more cognitively and socially congruent with their learners, leading to teaching that better meets learners' needs in more relaxed learning environments. In addition, students tend to view trainee doctors as equally important role models when compared with senior clinicians. ${ }^{7}$ Students model professional attributes, work ethics, and values upon the trainees with whom they interact. Enthusiastic trainee doctors can also positively influence students' career choice, ${ }^{8}$ which is particularly relevant in light of current primary care workforce concerns.

\section{TRAINER AND PRACTICE PERSPECTIVE}

Evidence suggests, perhaps surprisingly, that trainers can be reticent in encouraging their trainees to teach. ${ }^{9}$ This may stem from concerns about the individual capability or experience of their trainee, or lack of priority placed on teaching skill development in the context of their trainees' overall professional development. Furthermore, GP trainees can feel that the hierarchical shift from the hospital to training practice places them back in a passive learning role, in which their potential as teachers is diminished when compared with previously held hospital posts. Trainees may therefore feel that little value is placed on teaching activity and view it is an optional component of their clinical training.

Views have not however been universally negative, and some trainers have recognised the benefits of involving trainees in practicebased teaching. These benefits include relieving time pressures, maintaining up-todate practice, succession planning, and possibly financial gain in terms of placement fees. The Australian Vertical Integration (VI) model offers a useful perspective on the broader placement learning environment. ${ }^{10}$ In this approach multidirectional symbiosis is encouraged, where learning and teaching roles are shared across all the learner stages. In practical terms this might involve the trainer taking an overarching supervisory role, while teaching and learning activities occur between the foundation level doctor, GP trainee, and medical students. Trainers in multilevel learner settings are more likely to encourage trainees to teach, and perceive the barriers as less significant than those at single-level learner practices.

\section{MEDICAL SCHOOL PERSPECTIVE}

Medical school placements in general practice have a powerful effect on students future career plans, yet UK medical students on average spend only $13 \%$ of their training time based in GP surgeries. ${ }^{11}$ Capacity for undergraduate GP placements is a serious challenge for many medical schools that could be partly addressed by increased involvement of trainees as near peer teachers. Some GP training programmes have established close relationships with their local medical school and provide regular opportunities for their trainees to teach undergraduates, for example, as part of Innovative/Integrated Training Posts (ITPs) in medical education. In addition to increasing capacity for student placements, such links provide trainees with greater awareness of career pathways involving medical education and academic practice, as well as opportunities to network with those already working in the field.

\section{BARRIERS}

Previous research has identified a 


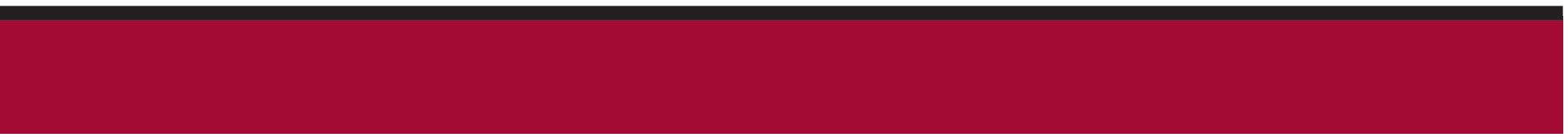

\section{"GP trainees represent a large, well-placed, but under- utilised educational resource.}

\section{ADDRESS FOR CORRESPONDENCE}

Harish Thampy

Stopford Building, Oxford Road, Manchester, M13 9PL, UK

Email: harish.thampy@amanchester.ac.uk range of barriers that may limit trainee engagement with teaching opportunities. Lack of protected time is often cited as a restriction. ${ }^{3}$ Consequently, already busy trainees place teaching as a lower priority than competing clinical needs and view this as additional work. ${ }^{12}$ Trainee doctors can struggle with juggling the various roles they are expected to adopt as clinicians and learners in their own right. Teaching others may be seen as one more role in an already pressured programme. Finally, concerns have been raised around how best to identify, develop, and monitor the teaching ability of the trainee. Consideration will be needed regarding both the trainee's clinical and teaching experience, and their personal interest in developing as an educator. The collaborative, spiral learning elements of the VI approach may well help in addressing many of these concerns.

\section{RECOMMENDATIONS}

We recommend that all postgraduate trainers and trainees proactively seek out teaching opportunities within GP posts. Trainers should routinely ensure that their trainees fully complete the teaching competency of the RCGP ePortfolio and are offered opportunities to teach. To this end, all training practices should be encouraged to engage in undergraduate teaching in cooperation with their local medical school. Multi-level learning and integrated educational models (such as VI) should be promoted in all primary healthcare settings as the cultural norm for general practice rather than the exception. We recommend that GP training programmes provide or commission regular 'teaching to teach' sessions and ensure that trainees are supported to teach within their training practice. If practice-based teaching opportunities are not available then on-campus teaching should be encouraged at local medical schools. Medical schools in turn should explore initiatives with local postgraduate training departments for trainees to engage with local university departments of general practice and primary care, for example, developing ITPs or Academic Clinical Fellowships in medical education. Additionally, medical schools should consider components of GP placements within curricula that explicitly require or would benefit from trainee input, and implement opportunities for GP trainees to teach. Finally, we recommend that the RCGP considers an additional, formal workplace-based assessment in teaching for MRCGP, requiring all trainees to be observed and to receive feedback on teaching. Further research should also be encouraged to explore barriers and facilitators to trainees teaching students in general practice.

\section{CONCLUSION}

Harnessing the energy and skills of GP trainees as near peer teachers is a relatively simple measure that could significantly increase the capacity for GP placements for medical students and other health professionals in training. We encourage all training programmes, training practices, and trainers to consider the recommendations above and to promote teaching among their trainees. Evidence shows that most GP trainees are keen to develop their teaching skills and that students in turn value teaching by their near peers. There are also benefits for patients, practices, and medical schools. So when it comes to near-peer teaching everyone's a winner!

\section{Harish Thampy,}

Senior Clinical Lecturer; Academic Lead for Assessment, Manchester MBChB Programme, Manchester.

\section{Hugh Alberti,}

Subdean for Primary and Community Care, School of Medical Education, Newcastle University, Newcastle upon Tyne.

\section{Liza Kirtchuk,}

GP Stage 2 Lead, King's Undergraduate Medical Education in the Community Team, School of Population Sciences and Health Services Research, King's College London School of Medicine, London.

\section{Joe Rosenthal,}

Professor of Primary Care Education, Department of Primary Care and Population Health, UCL Medical School, London.

\section{Provenance}

Freely submitted; not externally peer reviewed.

\section{Competing interests}

The authors have declared no competing interests.

DOI: https://doi.org/10.3399/bjgp19X700361

\section{REFERENCES}

1. Rushforth B, Kirby J, Pearson D. General practice registrars as teachers: a review of the literature. Educ Prim Care 2010; 21(4): 221-209.

2. Halestrap P, Leeder D. GP registrars as teachers: a survey of their level of involvement and training. Educ Prim Care 2011; 22(5): 310-313.

3. Williams B, Amiel C. General practice registrars as teachers: a questionnaire-based evaluation. JRSM Short Rep 2012; 3(3): 14.

4. Weiss V, Needlman R. To teach is to learn twice. Resident teachers learn more. Arch Pediatr Adolesc Med 1998; 152(2): 190-192.

5. de Villiers MR, Cilliers FJ, Coetzee F, et al. Equipping family physician trainees as teachers: a qualitative evaluation of a twelveweek module on teaching and learning. BMC Med Educ 2014; 14: 228

6. Kleinitz A, Campbell D, Walters L. General practice registrar perceptions on training medical students. Aust Fam Physician 2014 43(1): $64-67$

7. Sternszus R, Cruess S, Cruess R, et al. Residents as role models: impact on undergraduate trainees. Acad Med 2012; 87(9): 1282-1287.

8. Musunuru S, Lewis B, Rikkers LF, Chen H. Effective surgical residents strongly influence medical students to pursue surgical careers. J Am Coll Surg 2007; 204(1): 164-167.

9. Dodd J, Vickery A, van Osch H, Emery J. General practice registrar teaching roles - is there a need for shared understanding? Aust Fam Physician 2009; 38(1-2): 77-80.

10. Dick ML, King DB, Mitchell GK, et al. Vertical integration in teaching and learning (VITAL): an approach to medical education in general practice. Med J Aust 2007; 187(2): 133-135.

11. Harding A, Rosenthal J, Al-Seaidy M, et al. Provision of medical student teaching in UK general practices: a cross-sectiona questionnaire study. Br J Gen Pract 2015; DOI: https://doi.org/10.3399/bjgp15X685321.

12. Thampy H, Agius S, Allery LA. The motivation to teach as a registrar in general practice. Educ Prim Care 2013; 24(4): 244-250. 